\title{
Glucose tolerance and blood pressure: long term follow up in middle aged men
}

\author{
V V Salomaa, T E Strandberg, H Vanhanen, V Naukkarinen, S Sarna, T A Miettinen
}

Abstract

Objective-To investigate the role of glucose tolerance in the development of hypertension.

Design-Retrospective analysis of the results of a health check up in a group of clinically healthy middle aged men in the late 1960s (median year 1968). The subjects were invited to enter into a primary prevention trial for cardiovascular disease in 1974, when they underwent clinical examination for risk factors. The trial was completed in 1979, when the men were re-examined. Follow up was in 1986.

Setting-Institute of Occupational Health, Helsinki, Finland and second department of medicine, University of Helsinki.

Subjects-In all, 3490 men born during 1919-34 participated in a health check up in the late 1960s. In 1974, 1815 of these men who were clinically healthy were entered into a primary prevention trial for cardiovascular disease. On clinical examination 1222 of the men were considered at high risk of cardiovascular disease. Of these, 612 received an intervention and were excluded from the study. A total of 593 men were without risk factors. The study comprised all of the men who did not have an intervention $(n=1203)$. In 1979, 1120 men were re-examined, and in 1986945 men attended follow up. There were two groups for analysis: one comprising all subjects and the other comprising only men who were normotensive in 1968 and for whom complete information was available.

Interventions-By 1979, 103 men were taking antihypertensive drugs, and by 1986, 131 were taking antihypertensive drugs and 12 were taking drugs for hyperglycaemia.

Main outcome measures-Blood glucose concentration one hour after a glucose load, blood pressure, and body weight were measured in 1968, 1974, and 1979. In 1986 blood pressure and body weight were recorded.

Results - Men who were hypertensive in $1986 \mathrm{had}$ significantly higher blood pressures $(p<0.0001)$ and (after adjustment for body mass index and alcohol intake) significantly higher blood glucose concentrations one hour after a glucose load at all examinations than those who were normotensive in 1986. Regression analysis showed that the higher the blood glucose concentration after a glucose load in 1968 the higher the blood pressure during the following years. Those men between the second and third tertiles of blood glucose concentration in 1968 had a significantly higher risk of developing hypertension (odds ratio $1.71,95 \%$ confidence interval 1.05 to 2.77) compared with those below the first tertile.

Conclusion-In this study men who developed hypertension tended to have shown an increased intolerance to glucose up to 18 years before the clinical manifestation of their disorder. Blood glucose concentration one hour after a glucose load was an independent predictor of future hypertension.

\section{Introduction}

In the 1970s several cross sectional studies reported a close association between blood glucose concentrations after glucose challenge and blood pressure.$^{1-3} \mathrm{~A}$ recent study using population based data and oral glucose tolerance tests standardised according to the current recommendations of the World Health Organisation has confirmed this finding. ${ }^{4}$ To our knowledge, however, there have not been any follow up studies on this topic, and it is unlikely that cross sectional analysis could disentangle the complex interactions of blood glucose, blood pressure, and body mass index.

We assessed the independent role of blood glucose concentration after a glucose challenge as a predictor of development of hypertension and investigated temporal relations between glucose tolerance and the development of hypertension during follow up of 18 years.

\section{Subjects and methods}

The study population comprised 3490 male business executives born during 1919-34 who had participated in a general health check up sponsored by their employers in the late 1960s (the median year was 1968). In 1974 these men were invited to take part in a multifactorial primary prevention trial for cardiovascular disease. By then 70 men had died and 1605 were either unwilling to participate or were excluded because of illness. Subjects with a fasting blood glucose concentration $>10 \mathrm{mmol} / \mathrm{l}$, a systolic blood pressure $>200 \mathrm{~mm} \mathrm{Hg}$, or a diastolic blood pressure $\geqslant 115 \mathrm{~mm} \mathrm{Hg}$ were excluded.

Clinical examination showed that 1815 volunteers were healthy and were not taking drugs regularly. In all, 1222 of them had at least one of the following risk factors: serum total cholesterol concentration $>7.0 \mathrm{mmol} / \mathrm{l}$, serum triglyceride concentration $>1.7 \mathrm{mmol} / \mathrm{l}$, systolic blood pressure $>160 \mathrm{~mm} \mathrm{Hg}$, diastolic blood pressure $>95 \mathrm{~mm} \mathrm{Hg}$, smoked more than 10 cigarettes a day, relative body weight (weight $(\mathrm{kg}) \times 100 /$ height $(\mathrm{cm})-105)>120 \%$, glucose tolerance one hour after glucose load $(1 \mathrm{~g} / \mathrm{kg}$ of body weight of glucose orally) $>9.0 \mathrm{mmol} / \mathrm{l}$. Two measurements of all of the risk factors were required, except for the oral glucose tolerance test, which was performed only once. These men were considered to be at high risk of cardiovascular disease and were randomly grouped according to whether they had an intervention $(n=612)$ or not $(n=610)$. The rest of the volunteers $(n=593)$ were without risk factors and considered to be at low risk of cardiovascular disease.

Our study comprised those subjects who did not have an intervention. Those who did were not studied 
because intervention measures included drugs affecting both blood pressure and blood glucose concentration. Details of the intervention procedures have been published previously. ${ }^{56}$ If a subject included in the present study had a diastolic blood pressure $>110 \mathrm{~mm} \mathrm{Hg}$ he was advised to contact his own doctor. No other treatment or advice was given.

In 1979 the five year multifactorial primary prevention trial was completed and the subjects were reexamined. Eight men had died and 75 had dropped out; thus 1120 (93\%) of the 1203 subjects could be reexamined. At follow up in 1986 a further 40 men had died, 12 subjects could not be traced (although they were alive according to the National Population Register), and a further 123 had dropped out; hence $945(82 \%)$ of the eligible subjects could be re-examined.

None of the men were taking drugs in 1968 and 1974. In 1979 and $1986103(9 \%)$ and 131 (14\%) respectively were taking antihypertensive drugs. In 198612 (1\%) men were taking drugs for hyperglycaemia.

\section{MEASUREMENTS}

Blood pressure, body weight, and height were recorded in 1968, 1974, 1979, and 1986. Blood pressure was measured after 5-10 minutes' rest in the sitting position with a standard mercury sphygmomanometer. A measurement of oral glucose tolerance after one hour ( $1 \mathrm{~g}$ of glucose $/ \mathrm{kg}$ of body weight) was performed in 1968, 1974, and 1979. Blood glucose concentration was determined with an autoanalyser ${ }^{7}$ or by the method of Hultman. ${ }^{8}$ Self reported alcohol intake was recorded from 1974.

In the analyses a subject was considered hypertensive if his systolic blood pressure was $\geqslant 160 \mathrm{~mm} \mathrm{Hg}$ or diastolic blood pressure was $\geqslant 95 \mathrm{~mm} \mathrm{Hg}$ or if he was taking antihypertensive drugs.

Some information was missing, especially with respect to the 1968 examination, which was not originally planned to be part of a scientific study. Thus the blood glucose concentration one hour after a

TABLE I-Mean $(S D)$ systolic and diastolic blood pressures at follow up examinations in all men studied and men who were normotensive in 1968 and for whom complete information was available according to whether they were hypertensive or normotensive in 1986

\begin{tabular}{|c|c|c|c|c|c|c|}
\hline \multirow[b]{2}{*}{ Year of examination } & \multicolumn{3}{|c|}{ Hypertensive in 1986} & \multicolumn{3}{|c|}{ Normotensive in 1986} \\
\hline & $\begin{array}{l}\text { Systolic } \\
(\mathrm{mm} \mathrm{Hg})\end{array}$ & $\begin{array}{l}\text { Diastolic } \\
(\mathrm{mm} \mathrm{Hg})\end{array}$ & $\begin{array}{c}\text { No of } \\
\text { subjects }\end{array}$ & $\begin{array}{l}\text { Systolic } \\
(\mathrm{mm} \mathrm{Hg})\end{array}$ & $\begin{array}{l}\text { Diastolic } \\
(\mathrm{mm} \mathrm{Hg})\end{array}$ & $\begin{array}{c}\text { No of } \\
\text { subjects }\end{array}$ \\
\hline \multicolumn{7}{|l|}{ 1986: } \\
\hline All subjects & $153(16 \cdot 2)$ & $96(7 \cdot 5)$ & 330 & $131(11 \cdot 8)$ & $82(6 \cdot 7)$ & 562 \\
\hline Initially normotensive subjects & $153(16 \cdot 1)$ & $97(6.6)$ & 133 & $132(12 \cdot 1)$ & $82(6 \cdot 5)$ & 282 \\
\hline \multicolumn{7}{|l|}{ 1979: } \\
\hline All subjects & $145(15 \cdot 1)$ & $94(8 \cdot 5)$ & 305 & $130(13 \cdot 3)$ & $84(8 \cdot 0)$ & 514 \\
\hline Initially normotensive subjects & $142(13 \cdot 8)$ & $93(7 \cdot 9)$ & 133 & $130(12 \cdot 4)$ & $84(8 \cdot 2)$ & 282 \\
\hline \multicolumn{7}{|l|}{ 1974: } \\
\hline All subjects & $150(18 \cdot 6)$ & $96(11 \cdot 3)$ & 289 & $133(14 \cdot 3)$ & $85(9 \cdot 2)$ & 466 \\
\hline Initially normotensive subjects & $146(17 \cdot 3)$ & $94(11 \cdot 2)$ & 133 & $132(13 \cdot 2)$ & $85(9 \cdot 0)$ & 282 \\
\hline \multicolumn{7}{|l|}{ 1968: } \\
\hline All subjects & $139(14 \cdot 4)$ & $88(9 \cdot 4)$ & 318 & $129(10 \cdot 9)$ & $82(6 \cdot 9)$ & 547 \\
\hline Initially normotensive subjects & $134(9 \cdot 3)$ & $84(5 \cdot 5)$ & 133 & $128(9 \cdot 6)$ & $81(5 \cdot 8)$ & 282 \\
\hline
\end{tabular}

TABLE II-Mean (SD) glucose concentration one hour after glucose load at follow up examinations in all men studied and men who were normotensive in 1986 and for whom complete information was available according to whether they were hypertensive or normotensive in 1986

\begin{tabular}{|c|c|c|c|c|c|}
\hline \multirow[b]{2}{*}{ Year of examination } & \multicolumn{2}{|c|}{ Hypertensive in 1986} & \multicolumn{2}{|c|}{ Normotensive in 1986} & \multirow[b]{2}{*}{$\begin{array}{c}\mathrm{p} \mathrm{Value} \\
\text { (Between groups) }\end{array}$} \\
\hline & $\begin{array}{c}\text { Glucose } \\
\text { concentration } \\
(\mathrm{mmol} /)^{\star}\end{array}$ & $\begin{array}{c}\text { No of } \\
\text { subjects }\end{array}$ & $\begin{array}{c}\text { Glucose } \\
\text { concentration } \\
(\mathrm{mmol} / \mathrm{l})^{\star}\end{array}$ & $\begin{array}{c}\text { No of } \\
\text { subjects }\end{array}$ & \\
\hline \multicolumn{6}{|l|}{ 1979: } \\
\hline All subjects & $7 \cdot 78(2 \cdot 15)$ & 297 & $7 \cdot 18(2 \cdot 15)$ & 510 & 0.0002 \\
\hline Initially normotensive subjects & $7 \cdot 79(2 \cdot 20)$ & 133 & $7 \cdot 43(2 \cdot 18)$ & 282 & $0 \cdot 13$ \\
\hline \multicolumn{6}{|l|}{ 1974: } \\
\hline All subjects & $7.06(1.92)$ & 300 & $6.71(1.91)$ & 498 & 0.01 \\
\hline Initially normotensive subjects & $7 \cdot 20(1.93)$ & 133 & $6.72(1.90)$ & 282 & 0.02 \\
\hline \multicolumn{6}{|l|}{ 1968: } \\
\hline All subjects & $6.40(1.67)$ & 258 & $5.96(1.65)$ & 417 & 0.001 \\
\hline Initially normotensive subjects & $6.50(1.64)$ & 133 & $6.02(1.63)$ & 282 & 0.007 \\
\hline
\end{tabular}

^ Adjusted for age and body mass index in the appropriate year by analysis of covariance. glucose load was available for only 950 subjects in 1968. Moreover, different subjects dropped out in different phases of the study. Hence the mean blood pressure and blood glucose concentration after one hour were calculated in two ways: firstly, by using all available information on all subjects for that particular year, and, secondly, by including only subjects for whom there was complete information throughout the study and who were normotensive (blood pressure $<160 / 95 \mathrm{~mm} \mathrm{Hg}$ ) in 1968 (to avoid confounding by initial hypertension).

\section{STATISTICAL METHODS}

Data were analysed by the standard biomedical programs data package. ${ }^{9}$ The distributions of the blood glucose concentrations after one hour were checked, and the differences between the group means were examined by the analysis of covariance, adjusting for age, body mass index, and initial (1968) blood pressure when appropriate. The importance of blood glucose concentration after one hour as a predictor of future blood pressure was investigated by using stepwise linear regression analysis with a sequential model. Blood glucose concentration after one hour was put into the equation at the first step, age together with annual body mass index and alcohol intake as a set of variables at the second step, and the initial (1968) blood pressure (either systolic or diastolic according to the dependent blood pressure) at the third step. These analyses were repeated by using the mean blood glucose concentration after one hour in 1968 and 1974 as a predictor instead of one measurement. Finally, the role of blood glucose concentration after one hour as a risk factor for hypertension was investigated by dividing the 1968 blood glucose concentrations into tertiles and comparing the risk of hypertension in the lowest tertile with those in the middle and highest tertiles. The odds ratios were calculated by logistic regression analysis, adjusting for age, body mass index, alcohol intake, and initial blood pressures. Only subjects who were normotensive in 1968 were included in this analysis. Confidence intervals for the risk ratios were calculated according to the formula:

$$
(\beta(1.96) \pm \operatorname{SE}(\beta))
$$

All the reported $\mathrm{p}$ values are two tailed.

\section{Results}

Throughout the study the subjects who were hypertensive in 1986 had higher blood pressures than those who were normotensive in 1986, and the differences were highly significant $(p<0.0001)$ in each year both for systolic and diastolic blood pressure (table I). In subjects who were initially normotensive and for whom complete information was available the difference in initial blood pressures between those who were hypertensive and those who were normotensive in 1986 was smaller but still significant $(\mathrm{p}<0.0001)$ with respect to both systolic and diastolic blood pressure.

Throughout the observation period since 1968 the subjects who were hypertensive in 1986 had, after adjustment for age and annual body mass index, significantly higher blood glucose concentrations after a glucose load than subjects who were normotensive in 1986 (table II). Similar differences were observed for those who were hypertensive in 1986 but normotensive in 1968 and for whom complete information was available (table II). As those who developed hypertension had higher blood pressures in 1968 the analyses for that year were repeated, adding a blood pressure as a covariate. The mean (SD) differences in adjusted blood glucose concentration one hour after a glucose load remained significant $(6.32$ (1.72) v 6.00 (1.68) $\mathrm{mmol} / \mathrm{l}, \mathrm{p}=0.02$ in all subjects, and $6.43(1.69) v 6.06$ 
$(1.64) \mathrm{mmol} / \mathrm{l}, \mathrm{p}=0.04$ in subjects who were normotensive in 1968 and for whom complete information was available), indicating that glucose tolerance was impaired before the onset of hypertension in those who developed hypertension.

By prospective stepwise regression analyses for 1968 values glucose concentration after one hour was an independent predictor of future blood pressure (table III). Accordingly, the higher this value in 1968, the higher the blood pressure, especially systolic pressure, during the following years. The regression coefficients for both systolic and diastolic blood pressure remained significant in 1974 and 1986 after adjustment for age, annual body mass index and alcohol intake, and initia blood pressure. The percentage variation of blood pressure, however, accounted for by one measurement of blood glucose concentration one hour after a glucose load was only modest: by univariate analyses about $3 \%$ for systolic blood pressure and even less for diastolic blood pressure. When the mean of blood glucose concentrations after one hour in 1968 and 1974 was used instead of one measurement as a predictor of subsequent blood pressure the coefficients became stronger and the percentage variation by univariate analyses rose to $5.7 \%$ in 1986 for systolic blood pressure and $3.0 \%$ for diastolic blood pressure (table III). Exclusion of subjects taking antihypertensive drugs in 1986 did not change the coefficients substantially.

After allowing for age, body mass index, alcohol intake, and initial blood pressure by using logistic regression analysis the men between the second and third tertiles of the glucose tolerance after one hour test result in 1968 had a 1.71 times (95\% confidence interval 1.05 to 2.77 ) higher risk of having hypertension at follow up than those below the first tertile (table IV). Between the first and second tertiles the risk of future hypertension was smaller than that between the second and third tertiles but still 1.36 times $(0.84$ to $2 \cdot 22)$ higher than below the first tertile.

\section{Discussion}

Metabolic studies have suggested that hypertension is associated with, and possibly even caused by, insulin resistance. ${ }^{10-12}$ There has, however, been some disagreement about the role of insulin resistance in the initiation of hypertension ${ }^{13}$ and in the hypertension of people who are not diabetic. ${ }^{14}$

In the present study the glucose tolerance test results were higher throughout the whole observation period

TABLE III-Stepwise regression coefficients for predicting future blood pressure from 1968 values for blood glucose concentration one hour after a glucose load and from mean values in 1968 and 1974 by year of examination and percentage variation of blood pressure accounted for by regression model

\begin{tabular}{|c|c|c|c|c|c|c|c|}
\hline \multirow[b]{2}{*}{ Year of examination } & \multicolumn{2}{|c|}{ First step } & \multicolumn{2}{|c|}{ Second step } & \multicolumn{2}{|c|}{ Third step } & \multirow[b]{2}{*}{ No of subjects } \\
\hline & Coefficient & $\mathbf{r}^{2}$ & Coefficient & $\mathbf{r}^{2}$ & Coefficient & $\mathrm{r}^{2}$ & \\
\hline \multicolumn{8}{|c|}{ Systolic blood pressure } \\
\hline 1974: & & & & & & & \\
\hline $\begin{array}{l}\text { Concentration in } 1968 \\
\text { 1979. }\end{array}$ & $1 \cdot 92^{\star \star \star}$ & 0.032 & $1 \cdot 26^{\star \star \star}$ & $0 \cdot 140$ & $0 \cdot 74^{\star}$ & $0 \cdot 360$ & 761 \\
\hline Concentration in 1968 & $1 \cdot 61^{\star \star \star}$ & 0.027 & $1 \cdot 04^{\star \star}$ & $0 \cdot 120$ & 0.57 & 0.260 & 801 \\
\hline Mean concentration for 1968 and 1974 & $2 \cdot 27^{\star \star \star}$ & 0.045 & $1 \cdot 41^{\star \star \star}$ & $0 \cdot 124$ & $0 \cdot 81^{\star}$ & 0.257 & 754 \\
\hline \multicolumn{8}{|l|}{ 1986: } \\
\hline Concentration in 1968 & $1 \cdot 80^{\star \star \star}$ & 0.029 & $1 \cdot 39 \star \star \star$ & $0 \cdot 117$ & $0 \cdot 73^{\star}$ & 0.232 & 678 \\
\hline \multirow{2}{*}{\multicolumn{8}{|c|}{ Diastolic blood pressure }} \\
\hline & & & & & & & \\
\hline $\begin{array}{l}\text { Concentration in } 1968 \\
\text { 1979: }\end{array}$ & $0 \cdot 94 \star \star \star$ & 0.022 & $0 \cdot 52^{\star}$ & $0 \cdot 150$ & $0 \cdot 41^{\star}$ & $0 \cdot 271$ & 761 \\
\hline Concentration in 1968 & $0 \cdot 40$ & 0.005 & 0.08 & 0.096 & -0.05 & $0 \cdot 177$ & 801 \\
\hline Mean concentration for 1968 and 1974 & $40 \cdot 74^{\star \star}$ & 0.014 & $0 \cdot 20$ & 0.095 & -0.002 & $0 \cdot 173$ & 754 \\
\hline 1986: & & & & & & & \\
\hline Concentration in 1968 & $0 \cdot 84^{\star \star \star}$ & 0.020 & $0.63^{\star \star}$ & $0 \cdot 135$ & $0 \cdot 47^{\star}$ & $0 \cdot 190$ & 677 \\
\hline Mean concentration for 1968 and 1974 & $+1 \cdot 12^{\star \star \star}$ & 0.030 & $0 \cdot 69^{\star \star}$ & $0 \cdot 142$ & $0 \cdot 47^{\star}$ & $0 \cdot 194$ & 644 \\
\hline
\end{tabular}

${ }^{\star} \mathrm{p}<0.05 ;{ }^{\star \star} \mathrm{p}<0.01 ;{ }^{\star \star \star} \mathrm{p}<0.001$.

$\dagger$ Sequential model with forced entry of blood glucose concentration one hour after a glucose load at the first step, age together with annual body mass index and alcohol intake as a set of variables added at the second step, and the initial (1968) blood pressure (either systolic or diastolic) at the third step.
TABLE IV - Number (\%) of men who were hypertensive or normotensive in 1986 according to tertile of blood glucose concentration one hour after glucose load in $1968^{\star}$

Glucose concentration

after one hour in 1968 Hypertensive Normotensive Odds ratio $(95 \%$

\begin{tabular}{lccl}
$(\mathrm{mmol} / \mathrm{l})$ & in 1986 & in 1986 & confidence interval $)$ \\
\hline$\leqslant 5 \cdot 15(\mathrm{n}=198)$ & $48(24 \cdot 2)$ & $150(75 \cdot 8)$ & $1 \cdot 00$ \\
$5 \cdot 16-6 \cdot 65(\mathrm{n}=197)$ & $63(32 \cdot 0)$ & $134(68 \cdot 0)$ & $1 \cdot 36(0 \cdot 84$ to $2 \cdot 22)$ \\
$\geqslant 6.66(\mathrm{n}=185)$ & $73(39 \cdot 5)$ & $112(60 \cdot 5)$ & $1 \cdot 71(1.05$ to $2 \cdot 77)$
\end{tabular}

* Results only for men who were initially normotensive (blood pressure in $1968<160 / 95$ ).

† Second and third tertiles compared with the first tertile. Adjustments were made for age, body mass index, and alcohol intake in 1986 and initial systolic and diastolic blood pressure by logistic regression analysis. Confidence intervals were calculated according to the formula e $\left(\beta \pm{ }^{\mathrm{SE}}(\beta)\right)$.

in the men who were hypertensive in 1986 than in those who were normotensive in 1986 . In 1986 and 1979 this finding may have been confounded by the metabolic effects of antihypertensive drugs, but in 1974 and 1968 none of the men were taking drugs. Furthermore, this difference remained significant, although subjects with undiagnosed hypertension initially were excluded and statistical adjustments were performed for age, body mass index, and initial blood pressure difference. This suggests that there was a small impairment of glucose tolerance years before the onset of clinical hypertension. The impairment was most probably due to the increased insulin resistance in those who later developed hypertension. Thus although we have no direct data on plasma insulin concentration, we think that our finding indirectly supports the hypothesis that insulin resistance has a role in initiating hypertension.

Most of the regression coefficients for predicting the future blood pressures from blood glucose concentrations one hour after a glucose load were significant, but the percentage variation of blood pressure explained by the blood glucose concentrations was modest. On the other hand, the odds ratios for hypertension during the 18 year follow up were quite strong: there was a $71 \%$ and $36 \%$ higher risk of hypertension between the second and third and first and second tertiles of the blood glucose after one hour as compared with that below the first tertile. It would be important to find out whether these risk estimates are repeatable by using the values of glucose tolerance two hours after a glucose load standardised according to the current recommendations ${ }^{15}$ or whether the value after one hour is a better predictor.

There are several reasons why our analyses tend to underestimate the true association. Firstly, there is a high variability of glucose measurements after the glucose challenge, which leads to the "regression dilution" bias. ${ }^{16} 17$ The importance of this was shown by the considerable improvement of coefficients and $r^{2}$ values, when the mean of two measurements was used as a predictor instead of one measurement. Secondly the factors used in these analyses are intercorrelated. The highest correlation coefficient (a Pearson coefficient of 0.41 ) was between the systolic blood pressure in 1968 and the systolic blood pressure in 1986. Thus adjustment for the initial blood pressure gives conservative estimates. Thirdly, the nature of the mortality and those who dropped out was selective. Most probably men who were hypertensive and glucose intolerant were overrepresented in these groups, which leads to underestimating the association during follow up.

A problem in our study was that the 18 year follow up time was based on the health check up in 1968 which was not originally planned to be a part of a scientific study. The check ups were, however, performed in the same institute (the Institute of Occupational Health) by using standardised methodology, which has been documented. ${ }^{18}$ The subjects were a homogenous group of business executives representing the highest social class. They were highly 
co-operative in all phases of the study. The missing information at the initial stage occurred randomly and it is not likely to cause bias. Hence the problems related to the initial examination do not invalidate our findings.

In a cross sectional analysis the plasma glucose concentration one hour after a glucose load was, independently of body weight, associated with blood pressure, even in schoolchildren aged 9-12. ${ }^{3}$ In our follow up study the glucose concentration after one hour was a strong predictor of future hypertension in adults. Thus a latent abnormality of glucose metabolism and blood pressure may last for decades without clinical manifestation. It is often combined with dyslipidemia ${ }^{190}$ and may play an important part in the development of atherosclerosis and coronary heart disease.

We thank Ms Jaana Räbinä for secretarial help and the Finnish Foundation for Cardiovascular Research, Kymenlaakson Terveyden Turva, and Suomen Kulttuurirahaston Kymenlaakson rahasto for financial support.

1 Stamler J, Rhomberg P, Schoenberger JA, et al. Multivariate analysis of the relationship of seven variables to blood pressure: findings of the Chicago Heart Association detection project in industry, 1967-1972. F Chronic Dis $1975 ; 28: 527-48$

2 Jarret RJ, Keen H, McCartney M, et al. Glucose tolerance and blood pressure in two population samples: their relation to diabetes mellitus and hypertension. Int $\mathcal{F}$ Epidemiol 1987;7:15-24.

3 Florey C du V, Uppal S, Lowy C. Relation between blood pressure, weight, and plasma sugar and serum insulin levels in schoolchildren aged 9-12 years in Westland, Holland. BMF 1976; i:1368-71.

4 Reaven PD, Barret-Connor EL, Browner DK. Abnormal glucose tolerance and hypertension. Diabetes Care 1990;13:119-25.
5 Miettinen TA, Huttunen JK, Naukkarinen V, et al. Multifactorial primary prevention of cardiovascular diseases in middle-aged men. Risk factors changes, incidence and mortality. FAMA 1985;254:2097-102.

6 Naukkarinen VA, Strandberg TE, Vanhanen HT, Salomaa VV, Sarna SJ, Miettinen TA. Mortality rates after multifactorial primary prevention of cardiovascular diseases. Annals of Medicine 1989;21:441-6.

7 Kessler G, Lederer H. Fluorometric measurement of triglycerides. In: Skeges LT, ed Automation in analytical chemistry. New York: Mediad, 1966:341

Hultan E Rapid specific method for determination of aldosacharides in body fluids. Nanure 1959;183:108-9.

9 Dixon WJ, ed. BMDP statistical software. Berkeley: University of California Press, 1985.

10 Ferrannini E, Buzzigoli G, Bonnadonna R, et al. Insulin resistance in essential hypertension. $N$ Engl f Med 1987;317:350-7.

11 Modan M, Halkin H, Almog S, et al. Hyperinsulinemia. A link between hypertension, obesity and glucose intolerance. $\mathcal{F}$ Clin Invest 1985;75:809-17.

12 Fournier AM, Gadia MT, Kubrusly DB, Skyler JS, Sosenko JM. Blood pressure, insulin and glycemia in nondiabetic subjects. Am f Med 1986;80: $861-4$

13 Porta M, Molinatti GM. Insulin resistance in hypertension. $N$ Engl $\mathcal{F}$ Med 1988;318:383

14 Mbanya J-CN, Thomas TH, Wilkinson R, Alberti KGMM, Taylor R. Hypertension and hyperinsulinemia: a relation in diabetes but not in essential hypertension. Lancet 1988:i:733-4.

15 World Health Organisation Study Group. Diabetes mellitus. WHO Tech Rep Ser 1985; No 727 .

16 Gardner MJ, Heady JA. Some effects of within-person variability in epidemiological studies. F Chronic Dis 1973;26:781-95.

17 MacMahon S, Peto R, Cutler J, et al. Blood pressure, stroke and coronary heart disease. Part 1, prolonged differences in blood pressure: prospective observational studies corrected for the regression dilution bias. Lancet 1990;335:765-74.

18 Mattila S. Correlation between ECG abnormalities observed in health examinations and coronary heart disease in middle-aged men [Dissertation]. Helsinki, Finland: University of Helsinki, 1980. (Finnish with English summary.)

19 Zavaroni I, Bonora E, Pagliara M, et al. Risk factors for coronary artery disease in healthy persons with hyperinsulinemia and normal glucose tolerance. $N$ Engl f Med 1989;320:720-6.

20 Foster DW. Insulin resistance-a secret killer? N Engl f Med 1989;320:733-4.
Projet Retro-CI, Abidjan, Ivory Coast

Kevin M De Cock, MD,

director

Emmanuel Gnaore, MD, medical officer

Georgette Adjorlolo, MD, medical officer

Marie-France Lafontaine, computer specialist

Gilberte Yesso, MD, medical officer

International Activity, Division of HIV and AIDS, Center for Infectious

Diseases, Centers for Disease Control, Atlanta, Georgia, United States

M Miles Braun, MD, medical officer

William L Heyward, MD, chief

Centres Antituberculeux, Abidjan, Ivory Coast Issa M Coulibaly, MD, medical officer

Raymond Bretton, $\mathrm{MD}$, chief medical officer

Genevieve Bretton, MD, medical officer

Institute Pasteur de Cote d'Ivoire, Ivory Coast Guy-Michel Gershy-Damet, PHD, microbiologist

Correspondence to: Dr De Cock.

\section{Risk of tuberculosis in patients with HIV-I and HIV-II infections in Abidjan, Ivory Coast}

Kevin M De Cock, Emmanuel Gnaore, Georgette Adjorlolo, M Miles Braun, Marie-France Lafontaine, Gilberte Yesso, Genevieve Bretton, Issa M Coulibaly, Guy-Michel Gershy-Damet, Raymond Bretton, William L Heyward

\section{Abstract}

Objective-To examine the association between HIV-II infection and tuberculosis.

Design-Cross sectional study comparing the prevalence of HIV-I and HIV-II infections in patients with tuberculosis and in blood donors.

Setting-Abidjan, Ivory Coast, west Africa.

Patients-2043 consecutive ambulant patients with tuberculosis (confirmed pulmonary, presumed pulmonary, or extrapulmonary) and 2127 volunteer blood donors.

Main outcome measure-Prevalence of HIV-I and HIV-II infections as assessed by presence of serum antibodies.

Results-Overall rates of HIV infection were $40.2 \%$ in patients with tuberculosis $(26.4 \%$ positive for HIV-I, $\mathbf{4 . 7 \%}$ for HIV-II, and $\mathbf{9 . 0 \%}$ for both); and $10.4 \%$ in blood donors $(7.2 \%$ positive for HIV-I, $1.9 \%$ for HIV-II, and $1.3 \%$ for both). HIV-II infection was significantly more common in patients with all types of tuberculosis than in blood donors (97/2043, $4.7 \% v 40 / 2127,1.9 \%$; odds ratio $3.8 \%$, $95 \%$ confidence interval $2 \cdot 6$ to $5 \cdot 6$ ).

Conclusion-Both HIV-I and HIV-II infection are associated with tuberculosis in Abidjan. $35 \%$ of adult tuberculosis in Abidjan is attributable to HIV infection and $4 \%$ specifically to HIV-II.

\section{Introduction}

Human tuberculosis is a recognised complication of infection with HIV-I. ${ }^{2}$ In the United States a relative increase in the incidence of tuberculosis has been found in areas with high rates of AIDS, affecting certain population groups with the highest incidences of AIDS most severely. ${ }^{3}$ Many seroepidemiological studies have shown high rates of HIV-I infection in patients with tuberculosis, and cohort studies in the United States ${ }^{4}$ and Zaire 5 have shown that patients infected with HIV-I are at increased risk of developing active tuberculosis.

Whether or not tuberculosis is an opportunistic disease complicating infection with HIV-II is uncertain. ${ }^{6}$ Although HIV-II infection is clearly associated with AIDS,${ }^{78}$ it has been suggested that the natural course of this infection differs considerably from that of infection with HIV-I (P Kanki et al, fifth international conference on AIDS, Montreal, 1989)..$^{90}$ Work from the Cape Verde Islands (D Andrade $e t a l$, third international conference on AIDS and associated cancers in Africa, Arusha, 1988) and Guinea-Bissau ${ }^{11}$ has suggested high levels of HIV-II infection in patients with tuberculosis, yet reports from Angola (M J M Almeida et al, fifth international conference on AIDS, Montreal, 1989), Benin (I Zouhoun et al, fourth international conference on AIDS, Stockholm, 1988), Mali (F Brun-Vezinet et al, fourth international conference on AIDS, Stockholm, 1988), and the Ivory Coast (M Braun et al, fifth international conference on AIDS, Montreal, 1989) did not show a definite association.

We compared levels of HIV-I and HIV-II infections in patients with tuberculosis and blood donors in Abidjan, Ivory Coast, where both viruses are present, 